\section{Key aspects of an effective surgical cu- rriculum for medical students}

To the Editor,

Surgery is a competitive specialty that a proportion of medical students choose to pursue however, many individuals find enhancing their portfolio difficult at such an early stage. This letter aims to provide a structured way in which surgically minded medical students can take advantage of opportunities to start to build a strong portfolio. There are 5 key areas to address throughout medical school: anatomy, clinical skills, management, research and mentorship. The overriding theme is that we must not only show an enthusiasm for surgical education, we must also be provided with an innovative and inspirational training programme.

\section{Anatomy Teaching}

Anatomy is traditionally taught by cadaveric dissection or prosection in medical schools. The use of cadaveric dissection and prosections must be preserved in medical schools, as this is

About the Author: Arthur is a final (6th) Year Medical Student at Newcastle University, United Kingdom and he has achieved a Master's by Research in Transplantation (with Distinction) from Newcastle University. During this degree he won a fellowship from Kidney Research UK and was shortlisted in the top 10 for the Royal Society of Medicine's Student Researcher of the year 2012/2013.

Submission: Jun 192013 Acceptance: Apr 252014 the most realistic simulation of the internal workings of the human body that pre-clinical students achieve prior to entering the operating theatre. Integration of newer techniques like 3D computer simulations of the human body will allow students to explore interactive prosections to understand and learn anatomy. For example, Anatomy TV $®$ is an internet based interactive learning tool derived from human dissection ( $w w w$. anatomy.tv). Orientating anatomy teaching around these tools will provide an innovative curriculum for pre-clinical students to learn.

There are several approaches to anatomy teaching however, we believe a case-based approach can help to teach normal anatomy and facilitate understanding of what problems abnormal pathology can cause. For example, when exploring the anatomy of the lungs this should be in the context of a disease such as cystic fibrosis; after learning the pathophysiology of the disease students will better understand the normal anatomy of the lung and how disruptions, such as bronchiectasis cause airway collapse, impaired clearance of secretions and increased susceptibility to infection. ${ }^{1}$ This approach can also help provide pre-clinical students with surgical treatments to these Figure 1. VOXEL-MAN Tempo 3D Surgical Simulator.

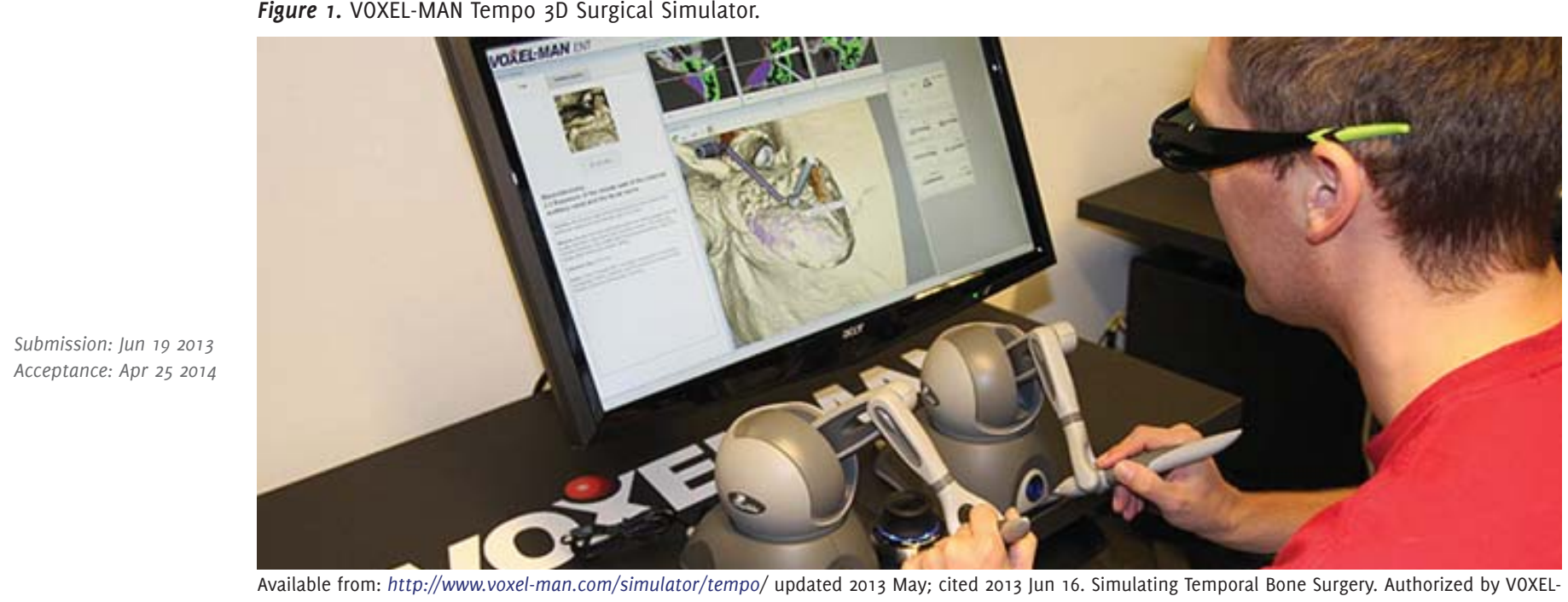

Available from: http://www.voxel-man.com/simulator/tempo/ updated 2013 May; cited 2013 Jun 16. Simulating Temporal Bone Surgery. Authorized by V0XELshould participate in and lead student bodies, such as the Stu- cases. For example, in the above case, the definitive treatment is a lung transplant. A case-based approach can help stimulate enthusiasm to learn anatomy.

Furthermore, the dissection room is also an ideal place for students to be introduced to the importance of good clinical practices such as hand washing and handling sharps. These skills are of vital importance for both patient and staff safety and have particular importance in a sterile surgical environment.

\section{Clinical and Technical Skills}

We must maximize all the learning opportunities available to us as medical students; this is especially important for those who train in the European Union because the European Working Time Directive restricts trainees to 48 hours of work per week, therefore surgeons of the future have less time to achieve the competencies held by surgeons of today. ${ }^{2}$ To achieve this, medical students must attend all clinical opportunities available to them, reading before and after each clinical experience to reinforce their knowledge base.

Surgical simulation has been shown to enhance (rather than substitute for) time in the operating room and surgical trainees and medical students widely agree that it should be added to their curriculum. ${ }^{3,4}$ Maximizing the use of surgical simulators available in some centres, will help budding surgeons build the necessary dexterity in order to succeed in surgical fields where procedures are progressively becoming minimally invasive. ${ }^{5,6}$ These early exposures will help clinical students develop and aspire to become the surgeons of tomorrow (Figure 1).

\section{Management and Leadership}

Surgery is more than a technical exercise; surgeons are team builders and leaders. Surgeons lead a multi-disciplinary team in the operating theatre and early experience of leadership can help develop communication and teamwork skills so that tomorrow's surgeons can become better leaders. Students dent British Medical Association (BMA) and surgical societies in order to gain experience in management and healthcare politics. Meanwhile, universities should provide opportunities for students to gain formal training in leadership and management 


\section{Correspondence}

as successful surgeons of tomorrow must have these qualities in their armamentarium of skills.?

\section{Research}

All medical professionals must innovate within their respective specialties and therefore as medical students we must involve ourselves in research, both opportunistically and through further degrees, to expand the evidence base from which we practice in the future. As students in active research centres, approaching senior practitioners to help with research projects and audits in a field of interest can be a great way of learning how boundaries can begin to be pushed and practice improved in surgery. The early development of analytical and critical thought to challenge and improve surgical care is important; the best surgeons need to move their specialty forward.

As future surgeons we have a unique chance to improve a specialty that is not traditionally academic there is a big push for clinical research with less than $1 \%$ of surgical patients currently involved in trials. ${ }^{8}$ Currently, despite a call for multicenter and even multinational collaboration, there is a reluctance by clinicians to recruit for research and therefore by improving our understanding of research methodology as students we can significantly contribute to evaluation of surgical procedures in all fields. 9,10

\section{Mentorship}

Lastly, we believe excellent surgeons need enthusiastic and committed mentors. Mentorship has been shown to ultimately maintain and improve patient surgical care." Mentors motivate, advise and may also be able to offer extra clinical or research exposure to enthusiastic students. Furthermore, it has even been shown that early preclinical mentorship positively influences student's decisions when embarking on a surgical career. $^{12}$

Therefore, universities should give students access to mentors that can guide and advise students on the correct path towards a successful future in a surgical speciality. As medical students, we can attempt to seek out these mentors ourselves by asking for opportunities to shadow and become involved in projects with surgeons that we take a liking to, that operate in a potential field of interest, or seem enthusiastic to teach.

Finally, during medical school, some students decide to embark on a surgical career than others. Regardless of the stage at which this decision is made it is important to maximize opportunities to give the best chance of success in our chosen field. We strongly believe that not only is embracing anatomy and clinical skills is important but also actively seeking leadership opportunities, research projects and mentors will give medical students the best chance of a successful career in surgery.

Arthur C. 0. Okonkwo, ' Okechukwu C. Okonkwo. ${ }^{2}$

'Medical student, Newcastle University Medical School, Framlington Place, Newcastle upon Tyne, NE2 4HH, United Kingdom.

${ }^{2} \mathrm{ST}_{4}$ Ear Nose and Throat Surgeon, North Manchester General Hospital, Delauanays Road, Manchester, M8 5RB, United Kingdom.

Arthur.okonkwo@gmail.com

Acknowledgments: None.

Conflict of Interest Statement it Funding: The Authors have no funding, financial relationships or conflicts of interest to disclose.

Author Contributions: Conception and design the work/idea: ACOO. Write the manuscript: ACO0. Critical revision of the manuscript: ACOO OCO. Approval of the final version: AC00. Administrative or technical advice: 0 CO.

Cite as: Okonkwo ACO, Okonkwo OC. Key aspects of an effective surgical curriculum for medical students. Int J Med Students. 2014 Mar-Jun;2(2):78-9.

\section{References}

1. Goeminne P, Dupont, L. Non-cystic fibrosis bronchiectasis: diagnosis and management in 21st century. Postgrad Med J. 2010 Aug;86:493-501.

2. Temple J. Time for training (Report). A review of the impact of the European working time directive on the quality of training. London: Medical Education England. 2010.

3. Palter VN, Grantcharov TP. Individualized deliberate practice on a virtual reality simulator improves technical performance of surgical novices in the operating room: a randomized controlled trial. Ann Surg. 2014 Mar;259(3):443-8

4. Glass CC, Acton RD, Blair PG, Campbell AR, Deutsch ES, Jones DB, et al. American College of Surgeons/Association for Surgical Education medical student simulation-based surgical skills curriculum needs assessment. Am J Surg. 2014 Feb;207(2):165-9.

5. Kehlet, H, Slim K. The future of fast track surgery. Br J Surg. 2012 Aug;99(8):1025-6

6. Kolga SM, Hedman L, Enochsson L, Kjellin A, Felländer-Tsai L. Systematic video game training in surgical novices improves performance in virtual reality endoscopic surgical simulators: a prospective randomized study. World J Surg. 2009 Nov;33(11):2360-7.

7. Exworthy M, Macfarlane F, Willmott M. NHS Management: 60 Years of Transition: A research Project Funded by the Nuffield Trust, London. 2009.

8. Søreide K, Alderson D, Bergenfelz A, Beynon J, Connor S, Deckelbaum DL, et al. Strategies to improve clinical research in surgery through international collaboration. Lancet. 2013 Sep 28;382(9898):1140-51.

9. Cooper C, Beard D, Carr A. What influences surgeons' experience of surgical research? Trails. 2013 Nov; 14(Suppl 1):P80

10. Diener MK, Simon T, Büchler MW, Seiler CM. Surgical evaluation and knowledge transfer--methods of clinical research in surgery. Langenbecks Arch Surg. 2012 Dec;397(8):1193-9.

11. Patel VM, Warren 0 , Ahmed K, Humphris P, Abbasi S, Ashrafian $\mathrm{H}$, et al. How can we build mentorship in surgeons of the future? ANZ J Surg. 2011 Jun;81(6):418-24.

12. Drolet BC, Sangisetty S, Mulvaney PM, Ryder BA, Cioffi WG. A mentorship-based preclinical elective increases exposure, confidence, and interest in surgery. Am J Surg. 2014 Feb;207(2):179-86. 